\title{
A field technique for rapid lithological discrimination and ore mineral identification: Results from Mamandur Polymetal Deposit, India
}

\author{
D Ramakrishnan*, M Nithya, K D Singh and Rishikesh Bharti \\ Department of Earth Sciences, Indian Institute of Technology Bombay, Mumbai 400 076, India. \\ ${ }^{*}$ Corresponding author.e-mail: ramakrish@iitb.ac.in
}

This work illustrates the efficiency of field spectroscopy for rapid identification of minerals in ore body, alteration zone and host rocks. The adopted procedure involves collection of field spectra, their processing for noise, spectral matching and spectral un-mixing with selected library end-members. Average weighted spectral similarity and effective peak matching techniques were used to draw end-members from library. Constrained linear mixture modelling technique was used to convolve end-member spectra. Linear mixture model was optimized based on root mean square error between field- and modelled-spectra. Estimated minerals and their abundances were subsequently compared with conventional procedures such as petrography, X-ray diffraction and X-ray fluorescence for accuracy assessment. The mineralized zone is found to contain azurite, galena, chalcopyrite, bornite, molybdenite, marcacite, gahnite, hematite, goethite, anglesite and malachite. The alteration zone contains chlorite, kaolinite, actinolite and mica. These mineral assemblages correlate well with the petrographic measurements $\left(R^{2}=0.89\right)$. Subsequently, the bulk chemistry of field samples was compared with spectroscopically derived cumulative weighted mineral chemistry and found to correlate well $\left(R^{2}=0.91-0.98\right)$ at excellent statistical significance levels (90-99\%). From this study, it is evident that field spectroscopy can be effectively used for rapid mineral identification and abundance estimation.

\section{Introduction}

Reflectance and emission spectra are extensively used to derive information on chemistry and atomic structure of various inorganic and organic compounds. Diagnostic absorption features in visibleand near-infrared (350-1000 nm) regions of spectra of minerals are mainly governed by electronic processes such as crystal field, charge transfer, conduction bands and colour centres (Adams 1974, 1975; Hunt 1977; Hunt and Ashley 1979; Clark et al. 1990a; Burns 1993). In longer wavelength regions (2000-16,000 nm), vibration processes involving stretching, rotation and bending of molecules are responsible for producing absorption features corresponding to fundamental, overtone and combination modes (Farmer 1974; Hunt 1982; Gaffey et al. 1993; Clark 1999). The position, shape, depth and width of these absorption features are governed by chemical composition and atomic structure of materials under investigation (van der Meer and De Jong 2006). In geological applications, such absorption features at characteristic wavelengths can be directly related to mineralogy (Hunt and Salisbury 1970; Clark 1999). Further, magnitude of spectral absorption at any specific wavelength can be related to abundance of constituent minerals (Clark et al. 1990b; Hapke 1993; Ramsey

Keywords. Field spectroscopy; linear mixture modeling; cumulative weighted mineral chemistry; mineral exploration. 
and Christensen 1998) within the field of view (FOV). In brief, reflectance/emission spectroscopy allows identification of minerals and quantitative estimation of their abundance. This ability of spectroscopy is being exploited by the remote sensing community in exploring the Earth and planetary surfaces for more than three decades (Goetz et al. 1985; Boardman and Huntington 1996; Mustard et al. 1998; Crosta and Filho 2000; Vaughan et al. 2003; Crouvi et al. 2006; van der Meer et al. 2006; Nowicki and Christensen 2007; Rogers and Christensen 2007; Galvo et al. 2008; Ramakrishnan and Kusuma 2008; Kusuma et al. 2010; Besse et al. 2011; Pour and Hashim 2011, 2012). With the advent of very compact and sophisticated spectrometers and spectroradiometers, field spectroscopy is evolving as a robust technique in mineral exploration and geological mapping (Kruse 1996; Vitorello and Galvao 1996; Thompson et al. 1999; Goetz et al. 2001; Herrmann et al. 2001; Sun et al. 2001; Yang et al. 2005; Goetz et al. 2009). Field spectroscopy also plays a key role in scaling-up of energy-matter interactions from field scale of a few centimetres to satellite pixel scale of a few metres (Gamon et al. 2006; Milton et al. 2009). However, understanding on various influence parameters such as source-sensor geometry, grain size, instrument calibration, spectral acquisition procedure, scheme of library spectral candidate selection and the appropriateness of unmixing procedure is vital for effective utilization of this technique.

In this study, we evaluated the efficacy of field spectroscopy for rapid identification and semiquantitative estimation of mineral assemblages representing ore body, alteration zones and host rocks in and around Mamandur Polymetal Deposit, India. This study is distinct from several of the published works (op. cit.) on aspects such as:

- acquisition of in situ reflection and emission spectra of large FOV (10-15 cm diameter) representing ore body, alteration zone and parent rocks;

- adoption of an automated spectral matching procedure to select the library spectral candidates and,

- validation of results estimated by spectroscopy for accuracy using petrography and geochemical analyses.

\section{Study area}

The Mamandur Polymetal Deposit (figure 1) is bounded by northern latitudes $11^{\circ} 52^{\prime}$ to $12^{\circ} 01^{\prime}$ and eastern longitudes $78^{\circ} 53^{\prime}$ to $78^{\circ} 59^{\prime}$. This

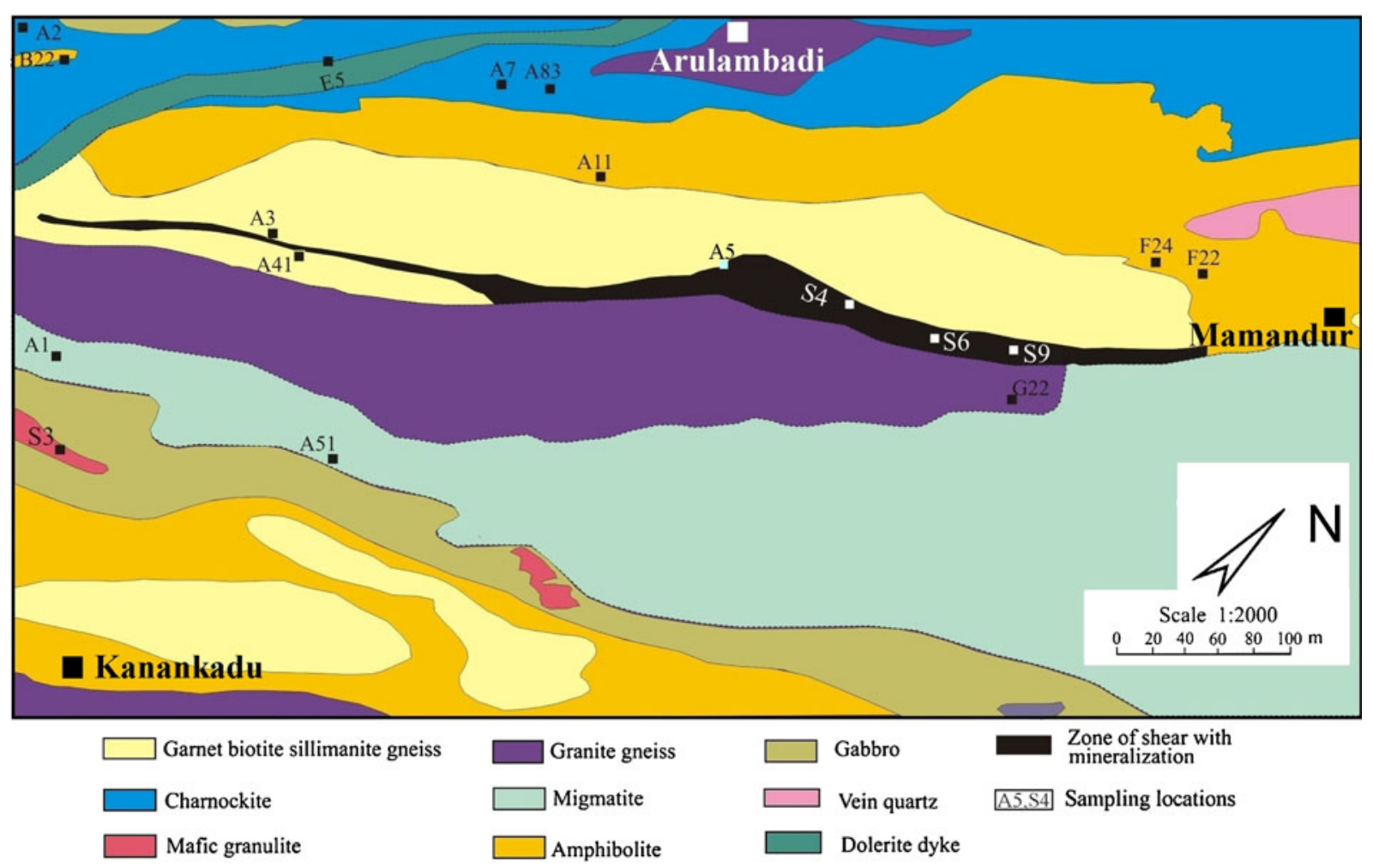

Figure 1. Location map of the study area indicating sampling sites. 

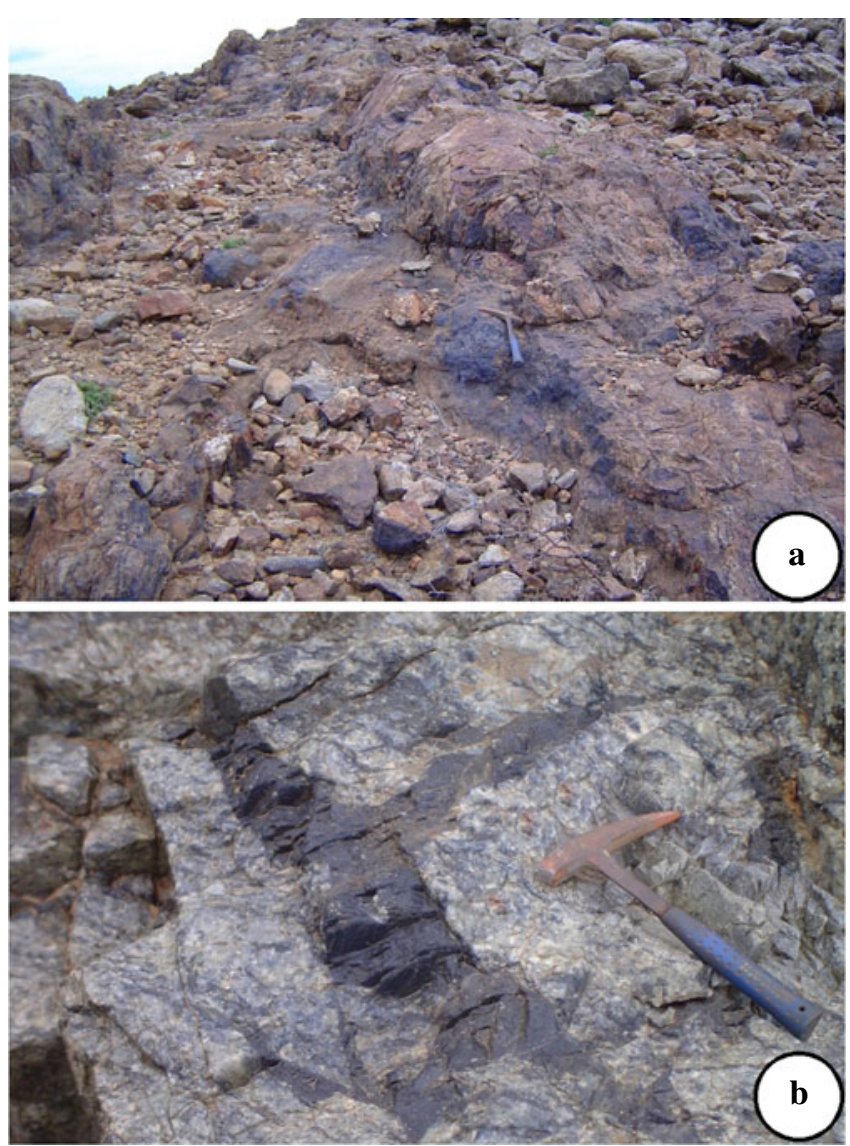

Figure 2. Field photographs depicting (a) zone of disseminated copper and (b) zone of multi-metal veins.

area is situated in the northern part of Southern Granulite Terrain comprising mostly migmatite and charnockite with bands of other high-grade metamorphic rocks such as banded-magnetitequartzite, garnet-biotite-gneiss, granite-gneiss and garnet-biotite-sillimanite-gneiss. These rocks are cut across by dykes of norite, dolerite, granite pegmatite and quartz veins (Chattopadhyay 1999). The $\mathrm{Pb}, \mathrm{Cu}$ and $\mathrm{Zn}$ mineralization in this area is associated with a shear separating migmatite complex in the east and amphibolitecharnockite in the west. In this deposit, mineralization occurs in two distinct zones. A disseminated copper lode occurs in the southern part (figure 2a) and a multi-metal mineralization zone with lead-zinc-copper and silver values occurs in the northern part (figure $2 \mathrm{~b}$ ). Wall rock alteration is manifested by alteration of biotite into chlorite, sericite; feldspars into kaolinite and alteration of pyroxene to tremolite and actinolite.

\section{Methodology}

The adopted methodology in this study involves (1) generation of a representative field spectral database for rock types, ore minerals and

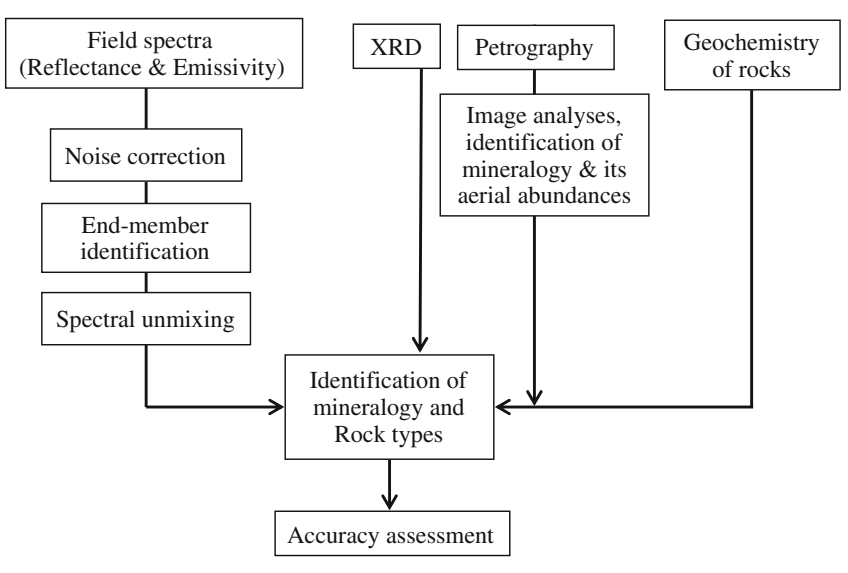

Figure 3. Flow chart depicting the adopted methodology.

hydrothermal alteration zones, (2) pre-processing of field spectra for noises, (3) spectral matching and un-mixing of field spectra for mineralogy and abundance estimation, and (4) mineralogical and geochemical analyses by conventional procedures to evaluate accuracy of spectroscopy-based procedure. The adopted methodology is shown as a flowchart (figure 3).

\subsection{Field spectra acquisition}

Reflectance and emission spectra were measured in the field at about 40 locations (with Global Positioning System (GPS) co-ordinates) representing rock types, alteration zones and ore bodies (figures 1 and 2) on a regular grid pattern. In order to achieve reproducibility, four consecutive spectral measurements were made with accumulation of 20 co adds at each location. While collecting reflectance spectra over alteration zones and ore body, very low FOV (10 cm diameter) was set to enhance effects of ore minerals. For host rock mapping, a larger footprint (15 cm diameter) emission spectra was collected to avoid the effects of big phenocrysts. The reflectance spectra (350$2500 \mathrm{~nm}$ ) were collected using ASD-Fieldspec3 portable field spectroradiometer with the Sun at its zenith and the sensor at about 10 degrees from zenith. Instrument calibration and spectral acquisition were carried out following the procedures of Salisbury (1998) using a spectralon panel.

The emissivity spectra (2000-16000 nm) were collected using D\&P 102F field Fourier Transform Infra Red Spectrometer (FTIR). This highly sophisticated instrument measures noise-equivalent temperature of $0.01^{\circ} \mathrm{C}$ and surface emissivity with an accuracy of 0.02 . The thermo-electrically calibrated blackbody (operating between $5^{\circ}$ and $60^{\circ} \mathrm{C}$ ) and diffuse gold plate were used to estimate the 
black body and down-welling irradiance. Once calibrated, sample radiance, blackbody spectra and down-welling radiances are estimated, the emissivity is calculated using equation (1).

$$
\operatorname{Es}_{(\lambda)}=\frac{\left[\operatorname{Ls}_{(\lambda)}-\operatorname{Ldwr}_{(\lambda)}\right]}{\left[B_{(\lambda, \mathrm{Ts})}-\operatorname{Ldwr}_{(\lambda)}\right]},
$$

where $\operatorname{Es}_{(\lambda)}$ - surface emissivity of sample as a function of wavelength; $\operatorname{Ls}_{(\lambda)}$ - calibrated radiance of sample; $\operatorname{Ldwr}_{(\lambda)}$ - calibrated down-welling radiance; $B_{(\lambda, T s)}$ is a Planck function at sample temperature.

\subsection{Pre-processing of field spectra}

The field spectra often contain wavelength specific and non-specific noises caused by atmospheric water vapour, gases, scattering and sensitivity of the instrument (Schmidt and Skidmore 2004; Ramsey et al. 2005). Noise, both coherent and non-coherent, can obscure characteristic spectral absorption features of minerals and reduce efficacy of spectral matching and convolution process. Therefore, pre-processing of field-spectra is necessary before they are used for mineral identification and abundance estimation (Schaepman and Dangel 2000; Liu et al. 2006). In this study, we observed that atmospheric constituents such as $\mathrm{H}_{2} \mathrm{O}, \mathrm{CO}_{2}$ and $\mathrm{N}_{2} \mathrm{O}$ reduce the upwelling signal strength and introduce noise from 2300 to $6000 \mathrm{~nm}$ wavelength regions. Since most of the alteration minerals have their absorption features within this window, noise removal is necessary before any spectral convolution is carried out.

In this work, we used the 'noise-to-signal index threshold' approach (Kusuma et al. 2010) to remove the noise from field spectra. This technique involves deriving a spectral index ' $R_{n}$ ' (equation 2) using spectra measured in field $\left[F_{(n)}\right]$ and in laboratory $\left[L_{(n)}\right]$ using the same instrument, FOV and source-sensor geometry. When there is an abrupt change in value of $R_{(n)}$ for any consecutive wavelength $(n)$, it can be inferred that this change is due to noise.

$$
R_{(n)}=\left(\frac{L_{(n)}-F_{(n)}}{L_{(n)}}\right)
$$

The ratio $\frac{\left[R_{(n+1)}-R_{(n)}\right]}{R_{n}}$ is then computed and, whenever value of this ratio exceeds a prescribed threshold value, $R_{(n+1)}$ is replaced in the equation $R_{(n+1)}=\frac{L_{n+1}-F_{n+1}}{L_{n+1}}$ by $R_{(n)}$ (or $R_{n}^{\prime}$, its corrected value) and appropriate value of field spectrum for band number $(n+1)$ is then calculated using equation (3).

$$
F_{n+1}=L_{n+1}-L_{n+1} \times R_{n} .
$$

For this study, minimum threshold values greater than 0.13 through 0.15 were used for the ratio $\frac{\left[R_{n+1}-R_{n}\right]}{R_{n}}$ to determine whether reflectance in $(n+1)$ th band needs noise correction. This range of threshold values was found to be efficient for spectra with sampling rate less than $4 \mathrm{~nm}$. At this optimized threshold range, we observed that both noise-reduction and preservation of field measured spectral features could be simultaneously achieved. Noise-corrected reference spectra (figure $4 \mathrm{a}, \mathrm{b}$ ) were subsequently convolved to their mineralogical constituents (i.e., end-members) and their fractional abundances by constrained Linear Mixture Model (LMM).
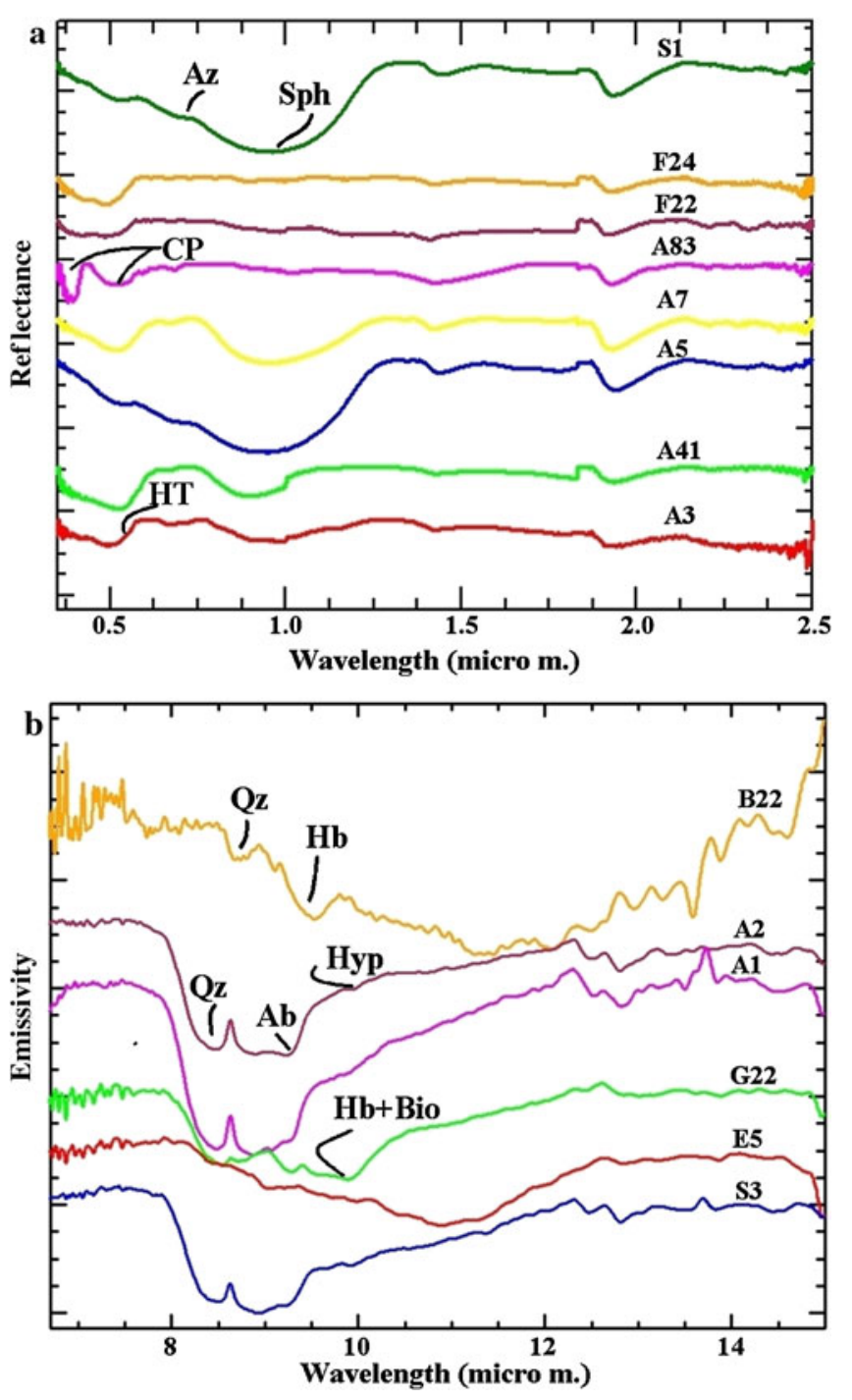

Figure 4. (a) Layer stacked reflectance spectra of ore body and alteration zones indicating absorption positions for various characteristic minerals such as chalcopyrite $(\mathrm{Cp})$, azurite $(\mathrm{Az})$, sphalerite (Sph), and hematite (Ht). (b) Emissivity spectra of host rocks indicating the presence of quartz $(\mathrm{Q})$, albite $(\mathrm{Ab})$, hornblende $(\mathrm{Hb})$, hypersthene $(\mathrm{Hy})$ and biotite (Bio). 


\subsection{End-member identification and mineral abundance estimation}

Field spectra are basically, weighted admixture of several spectrum representing minerals within FOV. Hence, successful interpretation of spectra depends on the efficiency of identifying constituent minerals (end-members) based on absorption features and subsequent estimation of their fractional abundances.

In this study, we followed a cascading spectral matching approach to identify the potential endmembers from the spectral library. In the first step, we have used Average Weighted Spectral Similarity (AWSS) as a measure of spectral similarity between each field spectrum and library spectra of minerals (Jet Propulsion Laboratory (JPL) and United States Geological Survey (USGS)). The AWSS was derived by taking weighted average of results estimated by spectral similarity algorithms such as Spectral Angle Mapper (SAM, Kruse et al. 1993), Spectral Feature Fitting (SFF, Clark et al. 1990b) and Binary Encoding techniques (BE, Mazer et al. 1988). An AWSS value, 1 indicates a perfect match between field and library spectra and value 0 indicates no match. In this study, we gave equal weight (0.33) to all three spectral matching algorithms and AWSS score of more than 0.80 was considered to identify the potential mineral. Since AWSS compares the entire feature vector, it is reasonably faster to reject the uncorrelated spectra from the library. Subsequently, the Effective Peak Matching (EPM) technique (Lau et al. 2000) was adopted to identify the potential end-member spectra (from AWSS pre-sorted population) based on the central wavelength, Full Width Half Maximum (FWHM) and depth of absorption features. Since EPM is an iterative process and computationally intensive, it is appropriate to apply this procedure on pre-sorted spectra.

In this work, absorption positions in reflectance spectra were used only to identify minerals containing transient elements (such as $\mathrm{Cu}, \mathrm{Zn}, \mathrm{Ag}$ and $\mathrm{Fe}$ ) and functional groups such as sulphides, sulphates, hydroxides and carbonates. Since depth of absorptions in reflectance spectra is influenced by other parameters such as grain size and source-sensor geometry (Bharti et al. 2012), we did not relate abundances of ore minerals to abundances alone. Further, quantitative estimation of ore minerals with aerial abundance lower than $10 \%$ is prone to errors (Feely and Christensen 1999). Hence, we limited the utility of reflectance spectra for mineral identification only. In case of emission spectra, a fully constrained linear mixing model (Mustard and Sunshine 1999) was adopted to identify the minerals and their abundances. Spectral unmixing (the process of decomposing original spectra into end-members and their abundances) results in estimation of contribution of individual component spectra $a(a=1, \ldots,\|A\|)$ to a target field spectrum containing a set $N$ of unknown $\|N\|$ spectral candidates, where $A \subset N$ and $\|A\|,\|N\|$ are the number of candidate spectra in $A$ and in $N$, respectively (Ramsey and Christensen 1998; Feely and Christensen 1999; Debba et al. 2006). Each of the component spectra $a$, which is derived from spectral library, consists of $L$ discrete wavelengths $\lambda_{l}(l=1, \ldots, L)$. It is denoted by $R^{e}=$ $\left(R^{e}\left(\lambda_{1}\right), \ldots, R^{e}\left(\lambda_{L}\right)\right)$, where $R^{e}\left(\lambda_{l}\right)$ is the emission value at wavelength $\lambda_{l}$. An observed spectrum $U=\left(U\left(\lambda_{1}\right), \ldots, U\left(\lambda_{L}\right)\right)$ is assumed to be a linear combination of $\|N\|$ end-members plus an addition term to attribute the error component. It is difficult to model target spectra $(U)$ for all probable components. Instead, the most promising subset $A$ of $N$ is often considered to estimate contribution of each one of the end-members using the relationship mentioned in equation 4.

$$
\hat{U}\left(\lambda_{l}\right)=\sum_{a=1}^{\|A\|} p_{e} R^{e}\left(\lambda_{l}\right)+p_{o} R^{N / A}\left(\lambda_{l}\right),
$$

where $0 \leq p_{e} \geq 1, p_{o}+\sum_{a=1}^{\|A\|} p_{e}=1$ is the contribution of each selected end-member of the spectral library, and $0 \leq p_{e} \geq 1$ is the fractional contribution of end-members. $R^{N / A}\left(\lambda_{l}\right)$ is an unknown linear combination of end-members. The resulting values of $p_{e}$ represent proportions of partial abundance of material of each of the spectral candidates considered to linearly model the field spectrum.

Once these initial estimates of end-members were obtained, an iterative least square curve fitting technique was adopted till we arrived at a satisfactory fit between modelled- and field-spectra (equation 5) using Matlab software.

$$
\operatorname{RMSE}=\sqrt{\frac{\sum_{\lambda=1}^{L}(U-\hat{U})^{2}}{N-1}},
$$

where $U$ is measured field spectra, $\hat{U}$ is modelled spectra and $L$ is the wavelength.

The appropriate combination of minerals and its abundance contributing to least Root Mean Square Error (RMSE) were considered to identify rocks. It is also observed that pre-selection of endmember spectra by AWSS and EPM helps in rapid optimization of RMSE.

\subsection{Petrography and geochemistry}

Mineralogy of samples collected from field (locations of spectral collection), were estimated by 
conventional procedures such as petrography and X-ray diffractometry (XRD). Aerial abundances of minerals were estimated using photomicrographs, ERDAS imagine and ARC/Info software following the procedure of Marschallinger and Hofmann (2010). Fractional aerial-abundance of each of the constituent minerals within the photomicrograph was computed by weighing the cumulative area occupied by each mineral to the total area of the photomicrograph. Unlike the modal abundances (Ramsey and Christensen 1998), this procedure allows precise aerial abundances of minerals irrespective of grain sizes. In addition to petrography, semi-quantitative mineralogy of samples was estimated using XRD (Rigaku D/MaxIC Cu $\alpha$ ) following the procedures of Goehner (1982).
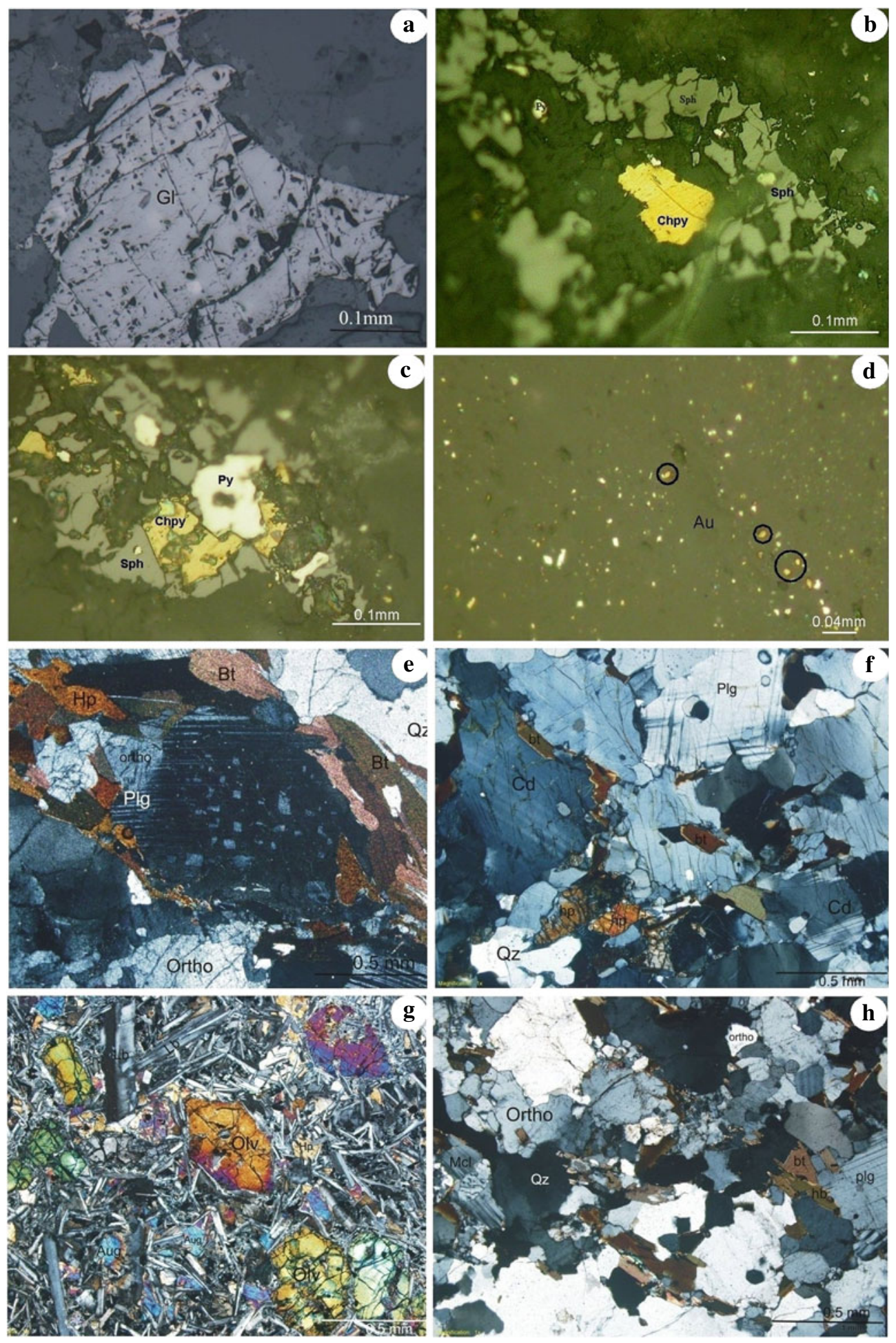

Figure 5. Photomicrographs of ore body $(\mathbf{a}-\mathbf{d})$ and host rocks $(\mathbf{e}-\mathbf{h})$ indicating mineralogy and textures. 


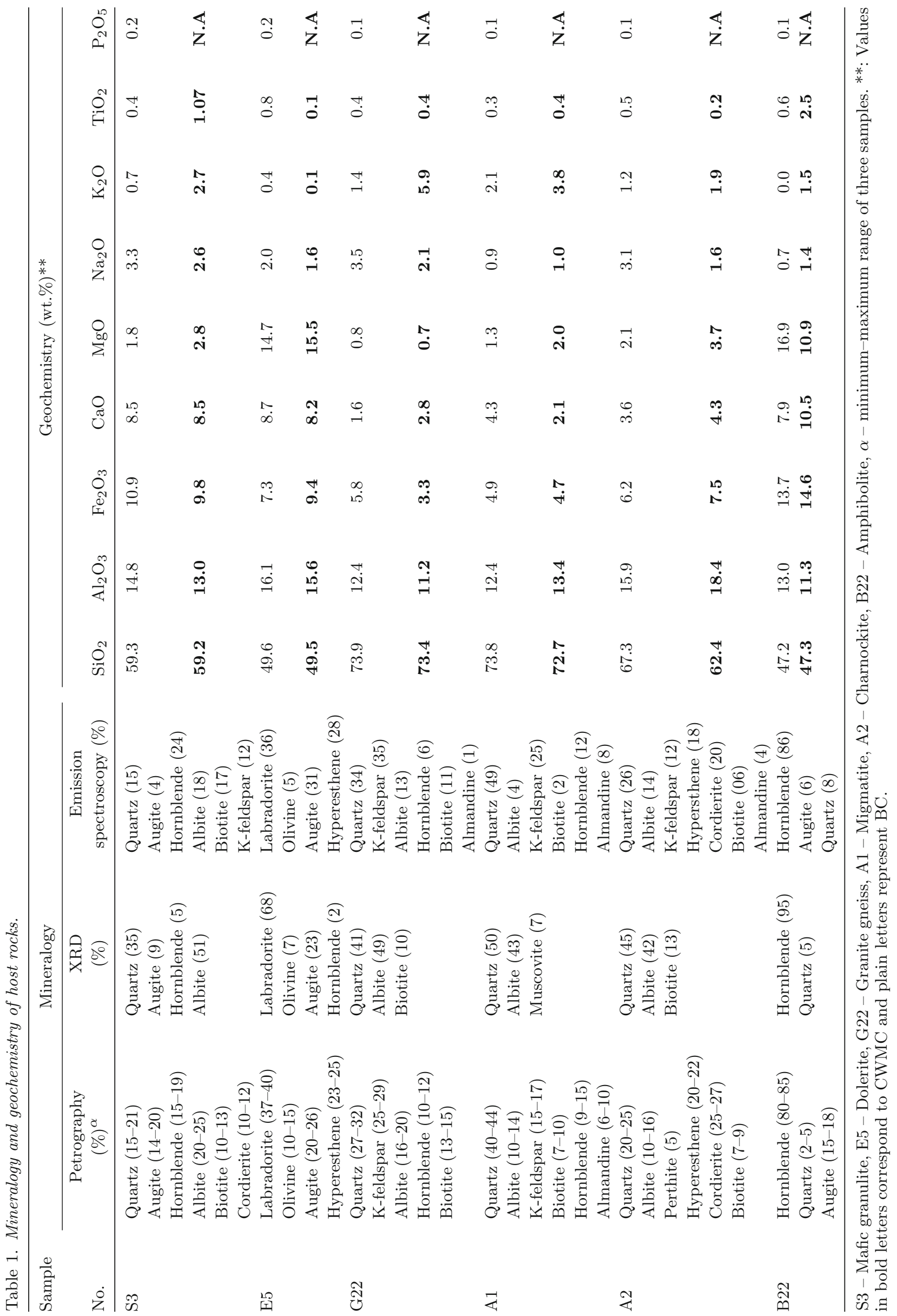


Table 2. Statistical relationship between $C W M C$ and $B C$ for the investigated rocks.

\begin{tabular}{|c|c|c|c|c|c|c|}
\hline \multirow[b]{2}{*}{ Statistical parameters } & \multicolumn{6}{|c|}{ Sample } \\
\hline & $\begin{array}{c}\text { Mafic } \\
\text { granulite (S3) }\end{array}$ & $\begin{array}{c}\text { Dolerite } \\
\text { (E5) }\end{array}$ & $\begin{array}{c}\text { Granite } \\
\text { gneiss (G22) }\end{array}$ & $\begin{array}{c}\text { Migmatite } \\
\text { (A1) }\end{array}$ & $\begin{array}{c}\text { Charnockite } \\
\text { (A2) }\end{array}$ & $\begin{array}{c}\text { Amphibolite } \\
\text { (B22) }\end{array}$ \\
\hline Regression coefficient $\left(R^{2}\right)$ & 0.98 & 0.98 & 0.91 & 0.92 & 0.97 & 0.85 \\
\hline Total degree of freedom $(d f)$ & 6 & 6 & 6 & 6 & 6 & 6 \\
\hline$F$-distribution (estimated) & 212 & 230.7 & 12.5 & 60.5 & 184.9 & 28.4 \\
\hline$F$-critical $(\mathrm{Fc})$ & 13.8 & 13.8 & 9.8 & 13.8 & 13.8 & 13.8 \\
\hline \multirow[t]{3}{*}{ Significance $(S)$} & $99 \%$ & $99 \%$ & $98 \%$ & $99 \%$ & $99 \%$ & $99 \%$ \\
\hline & \multicolumn{6}{|c|}{ Major oxides (for all rocks) } \\
\hline & $\mathrm{SiO}_{2}$ & $\mathrm{Al}_{2} \mathrm{O}_{3}$ & $\mathrm{Fe}_{2} \mathrm{O}_{3}$ & $\mathrm{CaO}$ & $\mathrm{MgO}$ & $\mathrm{Na}_{2} \mathrm{O}$ \\
\hline Regression coefficient $\left(R^{2}\right)$ & 0.89 & 0.87 & 0.83 & 0.81 & 0.99 & 0.70 \\
\hline Total degree of freedom $(d f)$ & 4 & 4 & 4 & 4 & 4 & 4 \\
\hline$F$-distribution (estimated) & 25.8 & 8.8 & 17.8 & 9.1 & 19.4 & 7.2 \\
\hline$F$-critical $(\mathrm{Fc})$ & 21.2 & 7.7 & 14.0 & 7.0 & 13.6 & 5.9 \\
\hline Significance $(S)$ & $90 \%$ & $95 \%$ & $98 \%$ & $96 \%$ & $98 \%$ & $93 \%$ \\
\hline
\end{tabular}
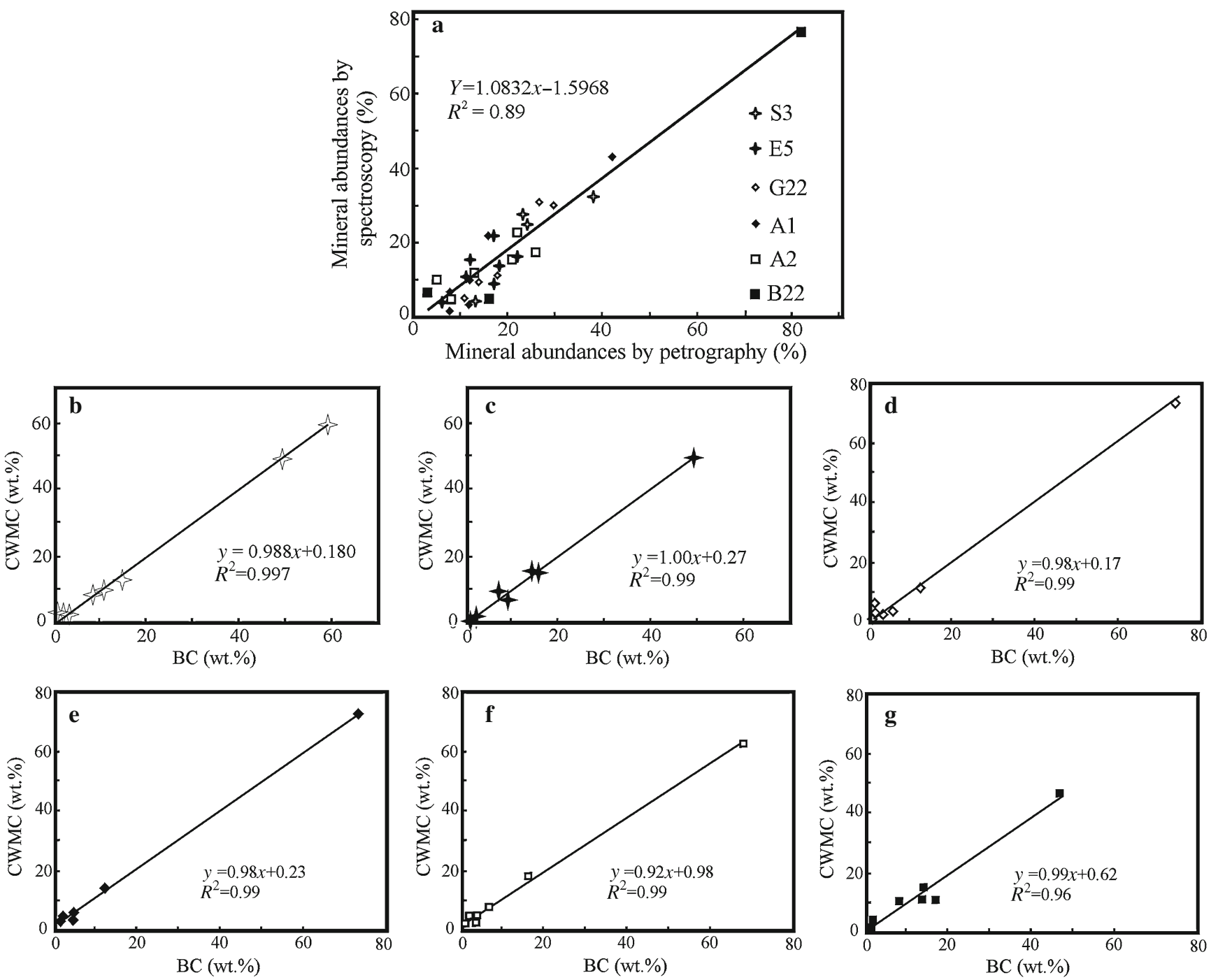

Figure 6. (a-g) Scatter plots indicating the relationship between spectroscopically derived and laboratory measured mineralogy (a) and major oxide geochemistry $(\mathbf{b}-\mathbf{g})$ for rocks of the investigated area. 
X-ray fluorescence (XRF, PW 2404) technique was used to estimate the bulk (major oxides) geochemistry, and the instrument was calibrated using the USGS standards Sco-1, SGR-1 and Sdo-1 (Govindaraju 1994). The weight percentage of estimated major oxides was used to identify lithology in conjunction with petrography results. In this study, we have also attempted to relate Bulk Chemistry (BC) of rocks to Cumulative Weighted Mineral Chemistry (CWMC). The CWMC was estimated by adding weighted fractions of pure mineral chemistry available with JPL spectral library. The weight fractions of each constituent mineral correspond to mineral abundances of rocks estimated by spectral convolution technique described earlier.

\section{Results}

\subsection{Mineralogy and geochemistry of ore bodies, alteration zones and host rocks}

From ore petrography studies (figure $5 \mathrm{a}-\mathrm{d}$ ), it is clear that pyrite (Py), chalcopyrite (Chpy), galena (Gl), sphalerite (Sph) are the main sulphide minerals in this prospect. In addition to these, small amounts of scheelite, malachite, marcasite, azurite, gold, bornite, pyrrhotite and molybdenite are also present in some samples. Though the above minerals are found in varying amounts, two dominant mineral associations can be distinctly observed. This includes a zone of sphaleritegalena-chalcopyrite in northern parts (samples $\mathrm{S} 4$, S6, S9) and a zone of chalcopyrite, pyrite (samples A5, A83) in southern parts of mineralization. The chalcopyrite and sphalerite are found in many forms and shapes. It is usually found as mediumto coarse-grained crystals with inter-granular and cataclastic texture with pyrite and pyrrhotite (figure 5b). Occasionally, exsolution lamellae and blebs of chalcopyrite can also be seen in sphalerite (figure 5c, d). Based on geochemistry, this prospect is predominantly rich in $\mathrm{Zn}(2.2-14 \%)$ with subordinate amount of $\mathrm{Cu}(0.16-1.0 \%)$ and $\mathrm{Pb}(0.17-1.86 \%)$. The alteration of host rock is mainly manifested by development of thin biotite, chlorite zones, alteration of feldspar into kaolinite and pyroxenes into actinoloite and tremolite (A5, Z2). At many places (A11, A41 and A7), the effects of secondary enrichment is evidenced by the prevalence of gossans.

In case of country rocks, it is clear that mafic granulites (figure 5e) contain about $55-60 \%$ of $\mathrm{Fe}-\mathrm{Mg}$ minerals (such as hypersthene [Hp], hornblende $[\mathrm{Hb}]$, biotite $[\mathrm{Bt}]$, and cordierite $[\mathrm{Cd}]), 35$ $40 \%$ of albite [plg] and quartz [Qz]. The charnockite (figure 5f) contains quartz (25-30\%), albite (8-10\%), orthoclase [ortho] (5-8\%), hyperesthene (15-20\%) and cordierite (25-30\%). The dolerite

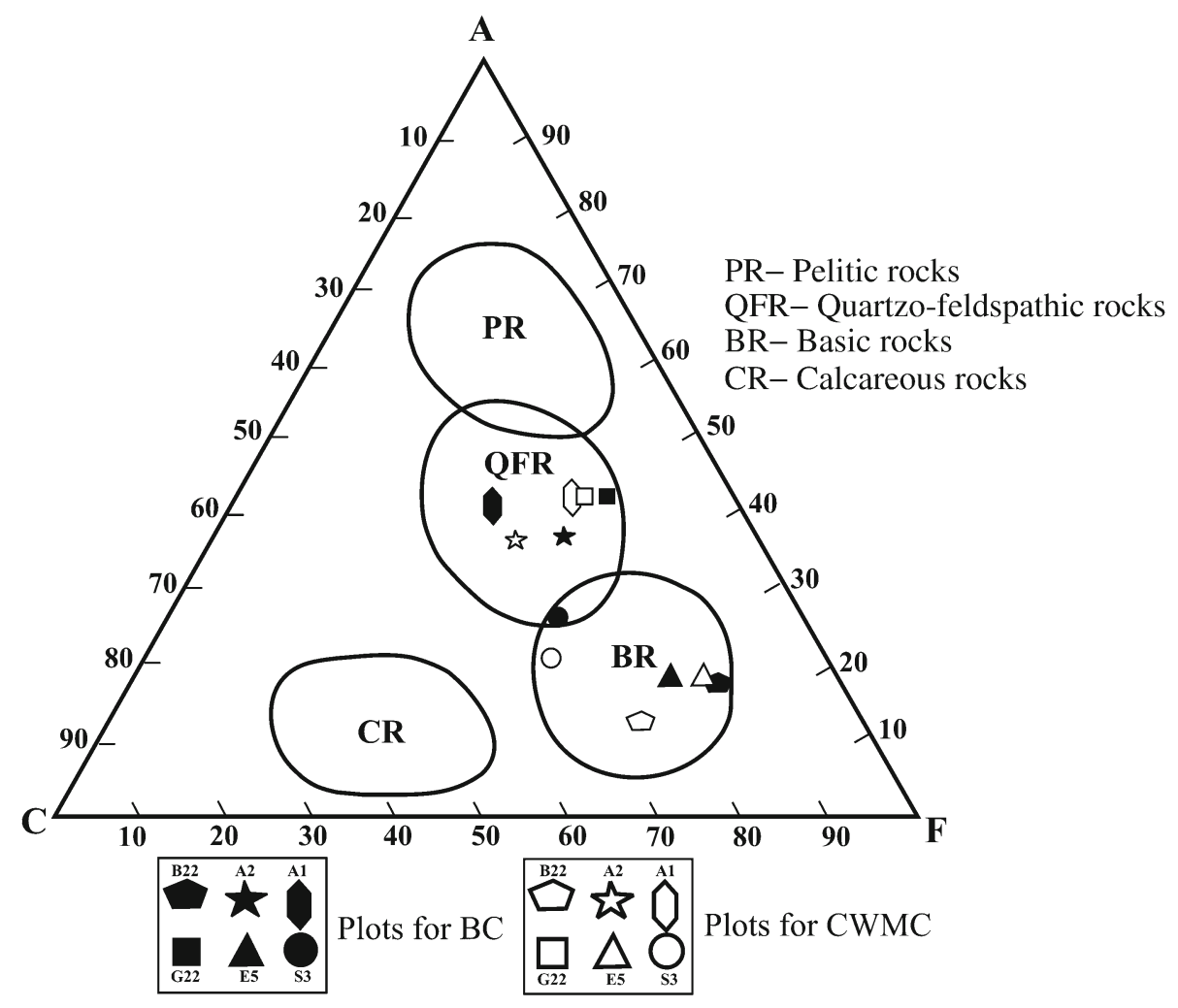

Figure 7. ACF ternary plots for host rocks made using BC (filled symbols) and CWMC (open symbols). 
dykes (figure $5 \mathrm{~g}$ ) were found to contain hypersthene (15-20\%) in addition to other essential minerals such as labradorite, olivine [Olv] and augite [Aug]. The migmatite and granite gneiss (figure 5h) have predominance of quartz (30-40\%) and potash feldspar (15-25\%) with subordinate amounts of albite, hornblende and garnet (table 1). It is also evident from table 1 that $\mathrm{BC}$ and $\mathrm{CWMC}$ match well for most of the major oxides $\left(\mathrm{SiO}_{2}, \mathrm{Al}_{2} \mathrm{O}_{3}\right.$, $\mathrm{Fe}_{2} \mathrm{O}_{3}, \mathrm{CaO}, \mathrm{Na}_{2} \mathrm{O}$ and $\mathrm{MgO}$ ). To statistically evaluate the relationship between these two procedures, regression coefficients, $f$-distribution and statistical significance were derived for each of the major oxides (table 2, figure 6). In most of the cases, the correlation between BC and CWMC was very good $\left(R^{2}=0.80-0.99\right)$ at $90-98 \%$ significance levels.
To understand the utility of CWMC in lithological classification, we have plotted the results in Alumina-Calcium-Ferromagnesium (ACF) triangular diagram (Philpotts and Ague 2009). Depending on the field where molar proportions of $\mathrm{A}$ $\left(\left[\mathrm{Al}_{2} \mathrm{O}_{3}+\mathrm{Fe}_{2} \mathrm{O}_{3}\right]-\left[\mathrm{Na}_{2} \mathrm{O}+\mathrm{K}_{2} \mathrm{O}\right]\right), \mathrm{C}([\mathrm{CaO}]$ $\left.-3.33\left[\mathrm{P}_{2} \mathrm{O}_{5}\right]\right)$ and $\mathrm{F}([\mathrm{FeO}+\mathrm{MgO}])$ lie, rocks were grouped into one of the classes such as pelitic, quartzo-feldspathic, basic and calcareous. It is clear from the ACF plots (figure 7) that the basic granulites (circles), dolerite (triangles) and amphibolite (pentagons) lie appropriately within the field of basic rocks. Similarly, granite gneiss (squares), migmatite (ellipses) and charnockite (stars) lie within quartzo-feldspathic group of rocks. The plots for charnockite lie in the overlap region between quartzo-feldspathic rocks and

Table 3. Alteration zone mineralogy by reflectance spectroscopy.

\begin{tabular}{|c|c|c|c|c|c|c|}
\hline \multirow[b]{2}{*}{ Sample no. } & \multirow[b]{2}{*}{ Absorption features (nm) } & \multirow[b]{2}{*}{ Minerals } & \multicolumn{4}{|c|}{ Spectral similarity score } \\
\hline & & & SAM & $\mathrm{SFF}$ & $\mathrm{BE}$ & AWSS \\
\hline A3 (Gossan) & $\begin{array}{l}411,495,662,948,2202 \\
\quad 2290,2443\end{array}$ & Goethite & 0.94 & 0.97 & 0.91 & 0.95 \\
\hline \multirow[t]{4}{*}{ A5 (Alteration zone) } & \multirow[t]{4}{*}{$544,682,937,1661,2310$} & Goethite & 0.89 & 0.84 & 0.96 & 0.89 \\
\hline & & Chlorite & 0.85 & 0.90 & 0.88 & 0.87 \\
\hline & & Marcasite & 0.80 & 0.90 & 0.89 & 0.85 \\
\hline & & Azurite & 0.75 & 0.89 & 0.87 & 0.84 \\
\hline \multirow[t]{3}{*}{ A7 (Gossan) } & \multirow{3}{*}{$\begin{array}{l}524,672,967,2207 \\
2285,2408\end{array}$} & Goethite & 0.86 & 0.92 & 0.97 & 0.91 \\
\hline & & Scheelite & 0.88 & 0.96 & 0.79 & 0.87 \\
\hline & & Lepidocrucite & 0.85 & 0.93 & 0.98 & 0.91 \\
\hline \multirow[t]{2}{*}{ A11 (Gossan) } & \multirow[t]{2}{*}{$493,649,904,2205$} & Hematite & 0.82 & 0.89 & 0.85 & 0.84 \\
\hline & & Kaolinite & 0.88 & 0.83 & 0.88 & 0.85 \\
\hline A41 (Gossan) & $524,675,892$ & Hematite & 0.92 & 0.96 & 0.97 & 0.94 \\
\hline \multirow[t]{5}{*}{ A83 (Ore zone) } & \multirow{5}{*}{$\begin{array}{l}395,520,590,684,1016 \\
2202,2260,2231\end{array}$} & Marcasite & 0.88 & 0.95 & 0.99 & 0.93 \\
\hline & & Anglesite & 0.91 & 0.96 & 0.94 & 0.92 \\
\hline & & Chlacopyrite & 0.88 & 0.95 & 0.95 & 0.92 \\
\hline & & Molybdenite & 0.89 & 0.94 & 0.93 & 0.91 \\
\hline & & Bornite & 0.90 & 0.86 & 0.95 & 0.92 \\
\hline \multirow[t]{4}{*}{ F22 (Ore zone) } & \multirow{4}{*}{$\begin{array}{l}421,485,583,599,617 \\
675,761,862,987,1218, \\
2207,2320,2399\end{array}$} & Pyrrhotite & 0.94 & 0.96 & 0.91 & 0.93 \\
\hline & & Chlorite & 0.85 & 0.96 & 0.99 & 0.92 \\
\hline & & Marcasite & 0.84 & 0.96 & 0.96 & 0.91 \\
\hline & & Pyrite & 0.84 & 0.96 & 0.96 & 0.91 \\
\hline \multirow[t]{4}{*}{ F24 (Ore zone) } & \multirow{4}{*}{$\begin{array}{l}431,485,610,666,725 \\
801,892,996,1169,1346 \\
2207,2285,2310\end{array}$} & Bornite & 0.84 & 0.96 & 0.89 & 0.89 \\
\hline & & Dolomite & 0.85 & 0.97 & 0.82 & 0.87 \\
\hline & & Molybdenite & 0.81 & 0.95 & 0.84 & 0.86 \\
\hline & & Pyrrhotite & 0.84 & 0.96 & 0.73 & 0.84 \\
\hline \multirow[t]{4}{*}{ Z-1 (Ore zone) } & \multirow{4}{*}{$\begin{array}{l}529,691,942,1666,1789 \\
\quad 2315,2420\end{array}$} & Actinolite & 0.89 & 0.86 & 0.90 & 0.88 \\
\hline & & Azurite & 0.86 & 0.89 & 0.91 & 0.88 \\
\hline & & Atacamite & 0.86 & 0.89 & 0.91 & 0.88 \\
\hline & & Chlorite & 0.88 & 0.91 & 0.80 & 0.81 \\
\hline \multirow[t]{5}{*}{ Z-2 (Ore+alteration zone) } & \multirow{5}{*}{$\begin{array}{l}391,529,691,942,1789 \\
\quad 2315,2420\end{array}$} & Actinolite & 0.93 & 0.95 & 0.80 & 0.88 \\
\hline & & Goethite & 0.87 & 0.92 & 0.88 & 0.88 \\
\hline & & Azurite & 0.84 & 0.92 & 0.91 & 0.88 \\
\hline & & Chlorite & 0.92 & 0.93 & 0.80 & 0.87 \\
\hline & & Atacamite & 0.83 & 0.92 & 0.90 & 0.87 \\
\hline
\end{tabular}


basic rocks. Higher percentage of $(>40 \%) \mathrm{Fe}-\mathrm{Mg}$ minerals such as hypersthene and cordierite suggest that these could be intermediate charnockites. It is also apparent from figure 7 that geochemical classification of rocks made using BC (dark symbols) and CWMC (open symbols) commensurate significantly.

\subsection{Spectroscopy of ore bodies, alteration zones and host rocks}

Reflectance spectra of transition elements such as $\mathrm{Cu}, \mathrm{Zn}$ and $\mathrm{Fe}$ usually exhibit spectral absorptions related to crystal field and charge transfer effects in visible and near infra-red regions. Information about the radical group is usually obtained from absorption features related to vibration processes in longer wavelength regions. Since field reflectance spectra used in this study ranged from 0.3 to $2.5 \mu \mathrm{m}$ (figure $4 \mathrm{a}$ ), we could collect spectral information related to electronic process and some of the components of vibration processes from this window. In this study, we interpreted the minerals contributing to field spectra based on AWSS score between field- and library-spectra of various minerals (table 3). Library minerals with high AWSS score $(>0.80)$ were considered as potential constituent minerals. It is obvious from table 3 that spectra of unweathered ore body exhibits absorption features corresponding to mineral assemblages such as sphalerite $(0.46,0.49,0.65,2.32 \mu \mathrm{m})$, galena $(0.58,0.78 \mu \mathrm{m})$, chalcopyrite $(0.43,0.87 \mu \mathrm{m})$, bornite $(0.56 \mu \mathrm{m})$, pyrite $(0.44,0.63,1.09,1.97 \mu \mathrm{m})$ and pyrrhotite $(0.49,1.01,1.95 \mu \mathrm{m})$. The weathered parts of ore body have mineral assemblages of azurite $(0.75$, $2.27,2.35 \mu \mathrm{m})$, hematite $(0.53,0.64,0.87 \mu \mathrm{m})$ goethite $(0.42,0.48,0.65,0.94,2.21,2.42 \mu \mathrm{m})$ scheelite $(0.49,0.95,2.20,2.30,2.43,2.47 \mu \mathrm{m})$, anglesite $(2.21,2.42 \mu \mathrm{m})$ and malachite (0.77, $1.19,2.26,2.40 \mu \mathrm{m})$. Wall rock alteration within shear zone is evidenced by occurrence of absorption spectra corresponding to alteration minerals such as actinolite $(0.71,1.03,2.30,2.38 \mu \mathrm{m})$, kaolinite $(2.16,2.20 \mu \mathrm{m})$, chlorite $(0.71,0.88,1.10$, $2.32 \mu \mathrm{m})$ and albite $(2.6,3.55,8.56,9.56 \mu \mathrm{m})$ with high AWSS scores. Silicification is manifested by the presence of quartz veins with characteristic absorption features at 8.46 and $8.98 \mu \mathrm{m}$.

Since silicate minerals exhibit absorption features in longer wavelength regions, mineralogy of rocks (table 1) were primarily evaluated using FTIR spectra (figure 4b). We attempted to model field spectra representing various rocks as a fully constrained linear mixtures of mineral end-members using JPL spectral library. These modelled spectra were convolved using different proportions of
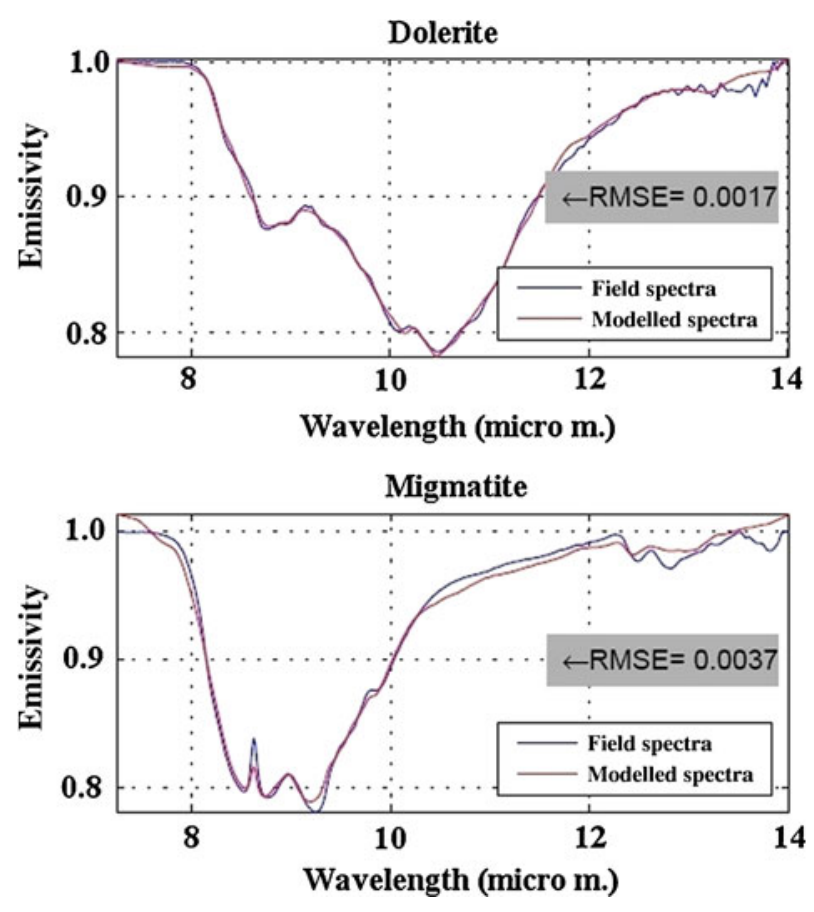

Figure 8. Plots depicting the match between field spectra (blue) and linearly modelled spectra (red) by using library end-members.

pure minerals to estimate their relative abundances. The goodness of fit between two spectra was evaluated based on least RMSE values (figure 8). It is clear from mineralogy (table 1) that rocks of the study area can be grouped into three major classes namely mafic rocks (dolerite, mafic granulite and amphibolite), intermediate rocks (charnockite) and acid rocks (migmatite and granite gneiss). Mafic rocks are an assemblage of plagioclase (18-36\%), pyroxenes (6-31\%), amphiboles (24-86\%), and subordinate amounts of olivine (4$5 \%)$. The charnockite comprises near-equal proportions of felsic (quartz and alkali feldspars) and mafic minerals (hypersthene, cordierite, biotite and garnet). The acid rocks are dominated by quartz (30-40\%) and alkali feldspars (25-45\%) with subordinate percentage of other minerals such as hornblende and biotite. It is also interesting to note that mineralogy and fractional abundance estimated by spectroscopy technique commensurate well with petrography-based estimates. However, mineralogy estimated by XRD has poor correlation with both petrography- and spectroscopy-based estimates.

\section{Discussion}

In Mamandur, the polymetal deposit has $\mathrm{Zn}, \mathrm{Pb}$ and $\mathrm{Cu}$ ores with an average grade of $5 \%, 1 \%$ and $0.6 \%$, respectively (GSI 1994). Part of the $\mathrm{Zn}$ is in 
the form of gahnite (zinc spinel), which is usually considered as a pathfinder for metamorphosed massive sulphide deposits (Spry 1987). Conventional procedures to study such ore mineralization involve detailed field mapping, sampling and extensive chemical and mineralogical analyses. In this study, we evaluated the efficacy of field spectroscopy in delineating various sub-zones within the deposit such as ore body, alteration zones and unaltered country rock. The results of spectroscopic-based approach were cross-checked with the results of conventional procedures for accuracy.

The procedures adopted in this study include collection of large FOV field spectra, their preprocessing for noise, identification of pure spectral library end-members, and linear unmixing of field spectra for mineral abundances. The earlier attempts to invert the mineralogy and their abundances from emission spectra (Ramsey and Christensen 1998; Feely and Christensen 1999; Debba et al. 2006) are based on laboratory measurements and hence, have limited utility in realtime mapping applications. In this study, we used the field reflectance and emission spectra with larger FOV so as to incorporate the effects of other influencing parameters such as source-sensor geometry, grain size variations and mineral alterations. Hence, this work has practical relevance and can also be considered as a link between laboratory and satellite-based measurements.

Presence of noise in target spectra can interfere with spectral matching. Hence, the field spectra were corrected for noise and subsequently, a cascading spectral matching procedure (using AWSS and EPM) was adopted. This approach is found to be advantageous in achieving optimized solution within least possible computation time (Singh et al. 2012). Inversion of field spectra using LMM (an over-determined system) with several constraints (such as least possible RMSE, sum to unity and non-negativity) is computationally intensive. Under such circumstances, it is faster to perform LMM with pre-selected end-members than involving all spectra in the library. Field spectra representing mineralized-, altered-zones, and host rocks were analysed by this technique and the constituent mineralogy deciphered. From the reflectance spectra, it is deciphered that the mineralized zone contains azurite, bornite, gahnite, chalcopyrite, anglesite, malachite and marcasite. Similarly, alteration zone comprise minerals such as chlorite, muscovite, actinolite and kaolinite. In case of host rocks, thermal emission spectra were used to identify various silicate mineral fractions in the host rocks (table 1).

To validate the results estimated by spectroscopy, destructive analyses such as petrography,
XRD and XRF were carried out. Most of the ore minerals (sphalerite, galena, chalcopyrite, bornite and pyrite) identified by spectroscopic technique (figure $4 \mathrm{a}-\mathrm{b}$ ) commensurate with the ore petrographic results (figure $5 \mathrm{a}-\mathrm{d}$ ). For silicate minerals, we have processed the photomicrographs to identify the minerals and compute their aerial abundances. This technique is advantageous to conventional modal analysis-based estimates as it can resolve very fine grains and is insensitive to grain size variations. It is evident from table 1 that the mineralogy estimated by petrography and spectroscopy are comparable. Scatter plots between the petrography- and spectroscopy-based abundance estimates (figure 6a) show high degree of correlation for all the analysed rocks. This high degree of correlation can be mainly attributed to precise estimation of aerial abundances by digital image processing technique. However, XRD results do not commensurate well with both methods, which could be attributed to heterogeneity in grain size, shape and orientation-related effects of mineral powder (Bish and Chipera 1988).

Once minerals and their abundances were estimated by LMM, we estimated major oxide geochemistry from the mineral chemistry (CWMC) and compared it with the results (BC) estimated using XRF. It is evident from table 1 and figure $6(\mathrm{a}-\mathrm{g})$ that results estimated by both $\mathrm{BC}$ and CWMC techniques correlate well $\left(R^{2}=0.71-0.98\right)$ and are statistically significant at very high levels $(98-99 \%)$. For each of the major oxides also, the $\mathrm{BC}$ and CWMC commensurate well $\left(R^{2}=\right.$ $0.7-0.99)$ and the relationships are statistically significant (90-98\%). ACF plots generated using BC and CWMC for all investigated rocks indicate that CWMC is as useful as BC in classification of rocks.

\section{Conclusion}

With the aid of field spectroscopy $\mathrm{Pb}, \mathrm{Cu}$ and Zn mineralization and associated alteration zones can be identified and mapped. Mineral variations within ore body, country rock and alteration zone can also be recognized in considerable detail because of their distinctive spectral characters. In this study, the results estimated by field spectroscopy commensurate well with the results generated by conventional procedures. Processing the field spectra for noise is necessary for efficient identification of ore, alteration and other silicate minerals. When reference spectra of rocks are convolved to estimates of mineral abundances, it is possible to identify lithology directly. In this study, LMM produced reasonably good mineral abundance estimates and hence can be considered as a 
proxy for conventional techniques. The major oxide chemistry estimated by field spectroscopy matches well with results estimated by XRF and can be directly used to discriminate the rock types in the field.

\section{Acknowledgement}

The authors are thankful to Department of Science and Technology, Government of India for financial support through research grant (NRDMS/11/1291/2007).

\section{References}

Adams J B 1974 Visible and near infrared diffuse reflectance spectra of pyroxenes and applied to remote sensing of solid objects in the solar system; J. Geophys. Res. 79 4829-4836.

Adams J B 1975 Interpretation of visible and near infrared diffuse reflectance spectra of pyroenes and other rock forming minerals; In: Infrared and Raman spectroscopy of lunar and terrestrial minerals (ed.) Karr C (California: Academic Press), pp. 94-116.

Besse S, Sunshine J M, Staid M I, Petro N E, Boardman $\mathrm{J}$ W, Green R O, Head J W, Isaacson P J, Mustard J F and Pieters C M 2011 Compositional variability of the Marius Hills volcanic complex from the Moon Mineralogy Mapper (M3); J. Geophys. Res. 116 E00G13.

Bharti R, Ramakrishnan D, Singh K D and Nithya M 2012 Relevance of mineral texture on bidirectional reflectance and emission spectroscopy: Implications for geological remote sensing; Proc. IGRASS - 2012, Munich, pp. 3046-3049.

Bish D L and Chipera S J 1988 Problems and solutions in quantitative analysis of complex mixtures by X-ray powder diffraction; In: Adv. X-ray Anal. (ed.) Barrett C, Plenum Publications 31 295-308.

Boardman J W and Huntington J H 1996 Mineral mapping with AVIRIS data; In: Summaries of the 6th Annual JPL Airborne Earth Science Workshop (Pasadena, California: JPL Publication) 96 4(1) 9-11.

Burns R 1993 Mineralogical applications of crystal field theory, 2nd edn (Cambridge: Cambridge University Press), $551 \mathrm{p}$.

Chattopadhyay P K 1999 Zn-spinel in the metamorphosed $\mathrm{Zn}-\mathrm{Pb}-\mathrm{Cu}$ sulphide deposit at Mamandur, southern India; Mineral. Mag. 63(5) 743-755.

Clark R N 1999 Spectroscopy of rocks and minerals: Principles of spectroscopy; In: Manual of remote sensing (eds) Rencz A and Ryerson R A, 3rd edn (New York: John Wiley and Sons), pp. 3-58.

Clark R N, King T V V, Klejwa M and Swayze G A 1990a High spectral resolution reflectance spectroscopy of minerals; J. Geophys. Res. 95 12,653-12,680.

Clark R N, Gallagher A J and Swayze G A 1990b Material absorption band depth mapping of imaging spectrometer data using complete band shape least square fit with library reference spectra; In: Proc. 2nd AVIRIS Workshop (Pasadena, California: JPL Publication) 90-54 176-186.

Crosta A P and Filho C R S 2000 Hyperspectral remote sensing for mineral mapping: A case-study at Alto
Paraiso De Goias, Central Brazil; Rev. Brasil. Geosci. 30(3) 551-554.

Crouvi O, Ben-Dor E, Beyth M, Avigad D and Amit R 2006 Quantitative mapping of arid alluvial fan surfaces using field spectrometer and hyperspectral remote sensing; Rem. Sens. Environ. 104 103-117.

Debba P, Carranza J M, van der Meer F D and Stein A 2006 Abundance estimation of spectrally similar minerals by using derivative spectra in simulated annealing; IEEE Trans. Geosci. Rem. Sens. 44(12) 3649-3658.

Farmer V C 1974 The infrared spectra of minerals (London: Mineralogical Society), 539p.

Feely K C and Christensen P 1999 Quantitative compositional analysis using thermal emission spectroscopy: Application to igneous and metamorphic rocks; J. Geophys. Res. 104(10) 24,195-24,210.

Gaffey S J, McFadden L A, Nash D and Pieters C M 1993 Ultraviolet, visible and near infrared reflectance spectroscopy: Laboratory spectra of geologic materials; In: Remote chemical analysis: Elemental and mineralogical composition (eds) Pieters C M and Englert P A J (Cambridge: Cambridge University Press), pp. 43-78.

Galvo S G, Formaggio A R, Couto E G and Roberts D A 2008 Relationships between the mineralogical and chemical composition of tropical soils and topography from hyperspectral remote sensing data; J. Photogram. Rem. Sens. 63 259-271.

Gamon J A, Cheng Y, Claudio H, Mackinney L and Sims D A 2006 A mobile tram system for systematic sampling of ecosystem optical properties; Rem. Sens. Environ. 103 $246-254$.

Goetz A F H, Vane G, Solomon J E and Rock B N 1985 Imaging spectrometry for earth; Rem. Sens. Sci. 228 1147-1153.

Goetz A F H, Chabrillat S and Lu Z 2001 Field reflectance spectrometry for detection of swelling clays at construction sites; Field Anal. Chem. Technol. 5 143-155.

Goetz F H A, Curtiss B and Shiley D A 2009 Rapid gangue mineral concentration measurement over conveyors by NIR reflectance spectroscopy; Mineral. Eng. 22 490-499.

Goehner R P 1982 X-ray diffraction quantitative analysis using intensity ratios and external standards; Adv. X-ray Anal. 25 309-313.

Govindaraju K 1994 Compilation of working values and descriptions for 383 geostandards; Geostandards Newslett. 18(S1) 1-158.

GSI 1994 Detailed information on copper-lead-zinc ores in Karnataka Andhra Pradesh and Tamil Nadu, India; Geological Survey of India, Unpublished report, 39-42.

Hapke B 1993 Theory of reflectance and emittance spectroscopy; (Cambridge, UK: Cambridge University Press), $513 \mathrm{p}$.

Herrmann W, Blake M, Doyle M, Huston D, Kamprad J, Merry N and Pontual S 2001 Short wavelength infrared (SWIR) spectral analysis of hydrothermal alteration zones associated with base metal sulphide deposits at Rosebery and Western Tharsis, Tasmania, and HighwayReward, Queensland; Econ. Geol. 96 939-955.

Hunt G R 1977 Spectral signatures of particulate minerals in the visible and near infrared; Geophysics 42 501-513.

Hunt G R 1982 Spectroscopic properties of rocks and minerals; In: Handbook of physical properties of rocks, (ed.) Carmichael R S (Boca Raton, Florida: CRC Press), pp. $295-385$.

Hunt G R and Ashley P 1979 Spectra of altered rocks in the visible and near infraraed; Econ. Geol. 74 1613-1629.

Hunt G R and Salisbury J W 1970 Visible and near infrared spectra of minerals and rocks: I Silicate minerals; Mod. Geol. 1 283-300. 
Kruse F A 1996 Identification and mapping of minerals in drill core using hyperspectral image analysis of infrared reflectance spectra; Int. J. Rem. Sens. 17(9) 1623-1632.

Kruse F A, Lefkoff A B, Boardman J B, Heidebrecht K B, Shapiro A T, Barloon P J and Goetz A F H 1993 The spectral image processing system (SIPS) - Interactive visualization and analysis of imaging spectrometer data; Rem. Sens. Environ. 44 145-163.

Kusuma K N, Ramakrishnan D, Pandalai H S and Kailash G 2010 Noise-signal index threshold: A new noise-reduction technique for generation of reference spectra and efficient hyperspectral image classification; Geocarto Int. 25(7) 569-580.

Lau O W, Hon P K and Bai T 2000 A new approach to a coding and retrieval system for infrared spectral data: The 'effective peak matching' method; Vibr. Spectroscopy 23(1) 23-30.

Liu D, Zhang Y, Zhang B, Song K, Wang Z, Duan H and Li F 2006 Effects of sensor noise in spectral measurements on chlorophyll-a retrieval in Nanhu Lake of Changchun, China; J. Electromagn. Waves Appl. 20 $547-557$.

Marschallinger R and Hofmann P 2010 The application of object based image analysis to petrographic micrographs; In: Microscopy: Science, technology, applications and education (eds) Mendez-Vilas A and Diaz J (Badajoz, Spain: Formatex Research Centre Publications), pp. 1526-1532.

Mazer A S, Martin M, Lee M and Solomon J E 1988 Image processing software for imaging spectrometry data analysis; Rem. Sens. Environ. 24 201-210.

Milton E J, Schaepman M E, Anderson K, Kneubühler M and Fox N 2009 Progress in field spectroscopy; Rem. Sens. Environ. 113 92-109.

Mustard J F, Li L and He G 1998 Nonlinear spectral mixture modeling of Lunar multispectral data: Implications for lateral transport; J. Geophys. Res. - Planets 103 419-425.

Mustard J F and Sunshine J M 1999 Spectral analysis for earth science: Investigations using remote sensing data; Chapter 5; In: Manual of remote sensing (eds) Rencz A and Ryerson R A, 3rd edn (New York: John Wiley and Sons), 286p.

Nowicki S A and Christensen P R 2007 Rock abundance on Mars from the thermal emission spectrometer; $J$. Geophys. Res. 112 E05007 1-20.

Philpotts A and Ague J 2009 Principles of igneous and metamorphic petrology, 2nd edn, (New York: Cambridge University Press), pp. 454-457.

Pour B A and Hashim M 2011 Identification of hydrothermal alteration minerals for exploring of porphyry copper deposit using ASTER data, SE Iran; J. Asian Earth Sci. 42 1309-1323.

Pour B A and Hashim M 2012 Identifying areas of high economic-potential copper mineralization using ASTER data in Urumieh-Dokhtar Volcanic Belt, Iran; Adv. Space Res. $49753-769$.

Ramakrishnan D and Kusuma K N 2008 Marine clays and its impact on the rapid urbanization developments: A case study of Mumbai area using EO-1-Hyperion data;
In: Hyperspectral remote sensing and spectral signature applications (ed.) Rajendran S (New Delhi: New India Publishing Agency), pp. 53-64.

Ramsey M S and Christensen P R 1998 Mineral abundance determination: Quantitative deconvolution of thermal emission spectra; J. Geophys. Res. 103 577-596.

Ramsey E, Rangoonwala A, Nelson G, Ehrlich R and Martella K 2005 Generation and validation of characteristic spectra from EO-1 Hyperion image data for detect ing the occurrence of the invasive species Chinese tallow; Int. J. Rem. Sens. 26 1611-1636.

Rogers A D and Christensen P R 2007 Surface mineralogy of Martian low-albedo regions from MGS-TES data: Implications for upper crustal evolution and surface alteration; J. Geophys. Res. 112 E01003 1-18.

Salisbury J W 1998 Spectral measurements field guide, Unpublished report; U.S. Defense Technology Information Center Report ADA362372 82.

Schaepman M E and Dangel S 2000 Solid laboratory calibration of non-imaging spectroradiometer; Appl. Opt. 39 3754-3764.

Schmidt K S and Skidmore A K 2004 Smoothing vegetation spectra with wavelets; Int. J. Rem. Sens. 25 1167-1184.

Singh K D, Ramakrishnan D and Mansinha L 2012 Relevance of transformation techniques in rapid endmember identification and spectral unmixing: A hypespectral remote sensing perspective; Proc. IGRASS 2012, Munich, pp. 4066-4069.

Spry P G 1987 The chemistry and origin or zincian spinel associated with Aggeneys $\mathrm{Cu}-\mathrm{Pb}-\mathrm{Zn}-\mathrm{Ag}$ deposits Namaqualand South Africa; Mineralium Deposita 22 $262-268$.

Sun Y, Seccombe P K and Yang K 2001 Application of IR spectroscopy to define alteration zones associated with Elura zinc-lead-silver deposit NSW Australia; J. Geochem. Explor. 73 11-26.

Thompson A J B, Hauff P L and Robitaille A 1999 Alteration mapping in exploration: Application of short-wave infrared (SWIR) spectroscopy; Soc. Econ. Geol. Newslett. 39 16-27.

van der Meer F and De Jong S 2006 Imaging spectrometry: Basic principles and prospective applications (The Netherlands: Springer Publishers), 451p.

van der Meer F, Yang H and Lang H 2006 Imaging spectrometery and geological applications; In: Imaging spectrometry: Basic principles and perspective applications (The Netherlands: Springer Publishers), pp. 201-218.

Vaughan R G, Calvin W M and Taranik J V 2003 SEBASS hyperspectral thermal infrared data: Surface emissivity measurement and mineral mapping; Rem. Sens. Environ. $8548-63$.

Vitorello I and Galvao L S 1996 Spectral properties of geologic materials in the 400 to $2500 \mathrm{~nm}$ range: Review for applications to mineral exploration and lithologic mapping; Photo Interpretation 34 77-99.

Yang K, Lian C, Huntington J F, Peng Q and Wang Q 2005 Infrared spectral reflectance characterization of the hydrothermal alteration at the Tuwu $\mathrm{Cu}-\mathrm{Au}$ deposit Xinjiang, China; Mineralium Deposita 40 324-336. 